\title{
RESEARCH
}

Open Access

\section{Pattern of congenital heart disease among Egyptian children: a 3-year retrospective study}

Marwa Moustapha Al-Fahham ${ }^{1,2^{*}}$ and Yasmin Abdelrazek Ali ${ }^{3}$

\begin{abstract}
Background: Congenital heart disease (CHD) is a multifactorial birth defect which has variable demographic characteristics among children in different geographical areas. This study aimed to detect the distribution of demographic data, perinatal risk factors, types, age, and mode of presentation of CHD among Egyptian children.

Results: The medical records of 1005 patients were included. They were 545 males (54\%) and 462 females (46\%) with a ratio of 1.2:1. Acyanotic CHD was encountered in 79.2\%. Isolated ventricular septal defect and tetralogy of Fallot were the most common acyanotic and cyanotic lesions, respectively. The majority was diagnosed within the first year of life (86.7\%) and was born to young mothers (91.3\%). The accidental discovery of a murmur was the most frequent presentation (35\%). Heart failure was detected in 44\%, audible murmurs in $74.4 \%$, maternal illnesses in $54 \%$, consanguinity in $44.6 \%$, prematurity in $19.3 \%$, assisted reproduction in $11.7 \%$, family history of CHD in $9.2 \%$, abortions in $7.1 \%$, and extracardiac anomalies in $3.6 \%$ of the studied population. Down syndrome (DS) was the most commonly occurring chromosomal anomaly, and the atrioventricular septal defect was the most characteristic cardiac lesion found among them.
\end{abstract}

Conclusions: There is no sex predilection among Egyptian children with CHD. Most of the cases are diagnosed in early infancy. Accidental discovery of a murmur is the most common mode of presentation. A variety of predisposing risk factors are abundant in the Egyptian population. DS is the most common chromosomal anomaly linked to CHD. Establishment of a national medical birth registry containing all information about all births in Egypt is needed for adequate surveillance and monitoring of perinatal health problems and congenital birth defects so that preventive measures can be early implemented. Proper and detailed data collection should be fulfilled in the medical records of every single patient.

Keywords: Congenital heart defects, Perinatal risk factors, Consanguinity, Maternal illnesses, Maternal age

\footnotetext{
* Correspondence: $\mathrm{m} \_$alfahham5m@hotmail.com

'Pediatric Department, Faculty of Medicine, Ain Shams University, Cairo,

Egypt

${ }^{2}$ Al-Salam International Hospital/Doctor Residency Building, P.O. Box 11023,

Bneid Al Gar, Kuwait

Full list of author information is available at the end of the article
}

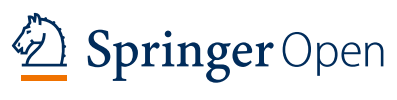

(c) The Author(s). 2021 Open Access This article is licensed under a Creative Commons Attribution 4.0 International License, which permits use, sharing, adaptation, distribution and reproduction in any medium or format, as long as you give appropriate credit to the original author(s) and the source, provide a link to the Creative Commons licence, and indicate if changes were made. The images or other third party material in this article are included in the article's Creative Commons licence, unless indicated otherwise in a credit line to the material. If material is not included in the article's Creative Commons licence and your intended use is not permitted by statutory regulation or exceeds the permitted use, you will need to obtain permission directly from the copyright holder. To view a copy of this licence, visit http://creativecommons.org/licenses/by/4.0/. 


\section{Highlights}

- The majority of patients (79.2\%) had acyanotic CHD.

- VSD is the most commonly encountered acyanotic CHD.

- Fallot's tetralogy is the most commonly occurring cyanotic CHD.

- No sex predilection among the studied population.

- Consanguinity is prevalent in $44.6 \%$ of the studied population.

\section{Background}

Congenital heart disease (CHD) is one of the relatively common congenital disabilities whose prevalence ranges from 3.5-17.5 per 1000 live births [1]. They are becoming an increasing cause of pediatric mortality [2], especially in the developing countries [3]. The clinical spectrum of CHD is versatile and changes according to the age of presentation. Asymptomatic presentation is common and discovered accidentally on routine checkup visits, whereas other presentations can range from poor suckling, cyanosis, and shortness of breath up to frank heart failure [4].

Most of these defects follow the multifactorial pattern of inheritance as a result of interlinking genetic and environmental factors with a smaller percentage being linked to chromosomal aberrations [5]. The pattern of risk factors for CHD is different among different parts of the world. In developing countries, consanguinity is relatively prevalent; most mothers are housewives, nonsmokers, and non-alcohol consumers [6]. Unfortunately, only a few studies had evaluated the perinatal risk factors among those populations [7].

A meticulous study of the epidemiology of CHDs is the cornerstone for better identification of the etiology for cardiac dysmorphogenesis so that every opportunity can be offered to prevent them prenatally [8-10]. Unfortunately, the epidemiology of CHD had not been thoroughly studied among Egyptian children; hence, this study aimed to review the risk factor portfolio, relative frequencies of each type of CHD, demographic characteristics, age, and mode of clinical presentations among Egyptian children with CHD; so that appropriate changes in preventive health policies can be implemented and optimum care for such patients can be provided.

\section{Methods}

This is a retrospective epidemiological cross-sectional study that included all children with confirmed CHDs who are registered in the Pediatric Cardiology Clinic at a Children's University Hospital which is considered a tertiary referral center that provides medical services for a large geographical sector in Cairo Governorate (mainly urban areas). Collaboration between all departments (pediatrics, cardiology, fetal ultrasound unit, and cardiothoracic surgery) takes place in this university hospital to provide all the necessary facilities needed for proper diagnosis and management of children with $\mathrm{CHD}$ (including advanced pediatric echocardiography, cardiac catheterization, fetal echocardiography, and cardiothoracic surgeries).

The study was conducted over a period of 3 years from January 2013 till December 2015. It included all children with confirmed structural CHD who were diagnosed from the first day of life up till the age of 12 years. Patients with congenital cardiomyopathies and congenital heart block were excluded from the study.

The files of 1005 patients were revised in detail. Some missing data were detected in 57 files and were completed by telephone calls when a valid number was available. Diagnosis of the type of CHDs was confirmed by echocardiography and documented in the files. Data collected included full demographic and clinical data. A thorough study of the perinatal (antenatal, natal, and postnatal), as well as the family history, was done to detect possible underlying risk factors for CHDs.

Demographic data included age at diagnosis, gender, sex, consanguinity, parental education, and occupation. For each studied case, the presenting complaint, type of CHD, presence of dysmorphic features, associated syndromes, or other congenital anomalies were all reported. Complete risk factor assessment was done for each reviewed file. Antenatal history included maternal age at conception, full obstetric history, repeated abortions or stillbirths, type of conception (normal or assisted), medical diseases with pregnancy (i.e., diabetes mellitus, hypertension, systemic lupus, and bronchial asthma), teratogen exposure (radiation, chemicals and smoking), maternal infection (i.e., urinary tract infection, congenital TORCH infections, and premature rupture of membranes), maternal medications during pregnancy (i.e., hypoglycemic, antihypertensive, antiepileptic, antibiotics). Natal and postnatal history included the gestational age (GA), early neonatal illnesses, and NICU admissions. Family history included the presence of CHDs, other congenital or chromosomal abnormalities, and sibling deaths.

\section{Statistical methods}

Data were collected, tabulated, and analyzed using SPSS, version 12. Mean and standard deviation were used for quantitative variables. Frequency and percentages were used for qualitative variables. 


\section{Results}

Over the 3 years study period, a total number of 1005 of patients were included. They were 543 males (54\%) and 462 females (46\%), their ages at diagnosis ranged from 1 day to 12 years with a median and interquartile range (IQR) of 6 (9-0.5) months. Of the studied population, acyanotic CHD was encountered in 796 (79.2\%) whereas cyanotic CHD in 209 (20.8\%). The isolated ventricular septal defect was the most common acyanotic CHD (19.8\%), while tetralogy of Fallot (9.8\%) was the most common cyanotic CHD. Small hemodynamically insignificant patent foramen ovale (PFO) and patent ductus arterisus (PDAs) were considered normal. Most of our patients had been diagnosed within the first year of life (48.9\% in the early infancy and $37.8 \%$ in the neonatal period). The relative frequencies and ages of presentations of individual types of CHDs are shown in Table 1.

The accidental discovery of a murmur was the most common presenting complaint (Fig. 1). Audible murmurs were detected in $748(74.4 \%)$ and heart failure in 442 (44\%) of patients. Hospital admissions were encountered in 469 patients; of them, 270 were admitted due to recurrent chest infections, 91 for cyanotic spells, 75 for failure to thrive, and 33 for neonatal sepsis-like illnesses. Life-saving cardiac interventions were performed in the first year of life for 33 patients; modified Blalock-Tausing shunt for 24 patients with tetralogy of Fallot and balloon atrial septostomy for 9 patients with TGA. Most of the patients $(91.3 \%)$ were born to young mothers aged $<29$ years, and $(66.3 \%)$ were born to multiparous mothers. Down syndrome was the most common chromosomal anomaly (10.4\%) found and atrioventricular septal (AVSD) defect was the most frequently occurring cardiac lesion among them (40.3\%). Fetal echocardiography was performed for 47 patients with assisted reproduction; of them, 18 patients had shown abnormal cardiac scanning. Distribution of demographic data and risk factors is shown in Table 2.

\section{Discussion}

Clinical presentation of CHD is versatile and is agedependent, and hence, a higher index of suspicion is needed for early diagnosis and treatment [11]. In this study, the commonest presentation for CHD was the accidental discovery (35\%) followed by recurrent chest infections $(30.2 \%)$, cyanosis (16.7\%), failure to thrive (13\%), neonatal sepsis-like illness (3.3\%), and finally shortness of breath (1.7\%). In a study done by Otaigbe and Tabansi [3], indications for screening echocardiography were auscultation of a murmur (36\%), rapid breathing $(19.8 \%)$, failure to gain weight (11\%), and cyanosis (9.9\%), whereas in a study done by George and FrankBriggs [11], fast breathing and inability to gain weight were the commonest presenting symptoms among CHD children.

Prevalence of murmurs is variable in different studies as it depends on the clinical skills, frequency, and timing of examination as nearly half of newborns with CHD will have no murmurs and possibly no other signs when examined at birth [12]. In this study, we detected audible murmurs in $74.4 \%$ of patients. Nearly 2 to 3 out of 1000 neonates with CHD will reveal symptoms during their first year of life. Diagnosis will be made by the first week in $40-50 \%$ and by the end of the first month in $50-60 \%$ of them [13]. In this study, most of our patients (86.8\%) were diagnosed below the age of 1 year $(37.8 \%$ in the neonatal period, and $49 \%$ within the first year of life). Similarly, in a study done by Subramanyan et al. [14], the ages at diagnosis of their CHD cases were in the early infancy and the neonatal periods in $40 \%$ and $38 \%$ of their studied population respectively.

In this study, we detected a male to female ratio of 1.2: 1. This matches with previous studies [3, 15]. Isolated VSD was the most prevalent acyanotic CHD. This matches with most of the previous studies $[3,8,15]$, whereas tetralogy of Fallot was the most frequent cyanotic CHD, which is also in agreement with most of the available studies [16-18].

$\mathrm{CHD}$ is the most common etiology for the occurrence of heart failure in infancy [19]. In the present study, we detected heart failure in $44 \%$ of the studied population. Similarly, Sommers et al. [20] detected heart failure in $39.1 \%$ of patients with CHD. The relatively higher prevalence of complications encountered in this study could be attributed to the lack of regular follow up and noncompliance to treatment, which eventually lead to the delay in surgical management.

About 15\% of CHD cases could be related to an underlying genetic cause, and a smaller percentage could be attributed to an environmental modifiable risk factor [21]. According to Liu et al. [22], nearly $14 \%$ of CHD cases could be prevented by avoidance of exposure to all known risk factors; however, some recent studies detected a higher percentage of about 30\% [21, 22]. Through this study, we tried to review the distribution of the perinatal risk factors-already known in literature among our studied population. This work was not designed to study them individually as predictors for the occurrence of CHDs; also, due to missing data in some files; not all the known risk factors were studied. This included maternal body mass index, smoking, anemia, nutritional status, and vitamin and folic acid supplementation during pregnancy.

In this study, the majority of our patients (91.7\%) belonged to housewives. Different maternal occupations have been linked to CHDs [23]. Scientific research has not yet confirmed the association between maternal 
Table 1 Frequency and age-wise distribution of types of CHD

\begin{tabular}{|c|c|c|c|c|c|c|}
\hline Age group & Neonatal & $>1$ month-1 year & $>1-<5$ years & $5-12$ years & Total & Percentage \\
\hline Isolated VSD & 60 & 105 & 28 & 6 & 199 & 19.8 \\
\hline Isolated ASD & 54 & 66 & 31 & 2 & 153 & 15.2 \\
\hline Tetralogy of Fallot & 45 & 39 & 12 & 3 & 99 & 9.8 \\
\hline AVSD & 40 & 50 & & & 90 & 8.9 \\
\hline Pulmonary stenosis ${ }^{a}$ & 10 & 54 & 11 & 8 & 83 & 8.3 \\
\hline ASD/NSD & 11 & 62 & & & 73 & 7.3 \\
\hline ASD/PDA & 14 & 42 & 1 & 1 & 58 & 5.8 \\
\hline Complex CHD & 40 & 17 & & & 57 & 5.7 \\
\hline VSD/PDA & 15 & 24 & & & 39 & 3.9 \\
\hline TGA & 31 & & & & 31 & 3.1 \\
\hline Mitral valve prolapse ${ }^{a}$ & & & 6 & 24 & 30 & 3 \\
\hline Coarctation of aorta & 18 & 10 & & & 28 & 2.8 \\
\hline Tricuspid atresia ${ }^{a}$ & 15 & & & & 15 & 1.5 \\
\hline Hypoplastic left heart & 4 & 10 & & & 14 & 1.4 \\
\hline TAPVR & & 13 & & & 13 & 1.3 \\
\hline Pulmonary atresia & 13 & & & & 13 & 1.3 \\
\hline Ebstein anomaly & 10 & & & & 10 & 1 \\
\hline Total & 380 & 492 & 89 & 44 & 1005 & \\
\hline Percentage (\%) & 37.8 & 48.9 & 8.9 & 4.4 & & 100 \\
\hline
\end{tabular}

ASD atrial septal defect; AVSD atrioventricular septal defects; PDA patent ductus arteriosus; TAPVR total anomalous pulmonary venous return; TGA transposition of great arteries; VSD ventricular septal defect

${ }^{\text {a }}$ Some patients are associated with septal defects

workplace exposure during pregnancy and the possible teratogenic effect on the forthcoming fetus, though there are still some concerns regarding exposure to pesticides, organic solvents, and heavy metals [24].

In Egypt, the prevalence of consanguinity is 29\% [25]. The relation between consanguinity and the incidence of
CHD had been explored in previous studies [26, 27]. We detected consanguinity and positive family history of CHD in $44.6 \%$ and $9.2 \%$ of our studied population, respectively. Similarly, Hag et al. [28] detected consanguinity and positive family history in $49 \%$ and $14 \%$ of their studied population, respectively, whereas Fung et al. [29]

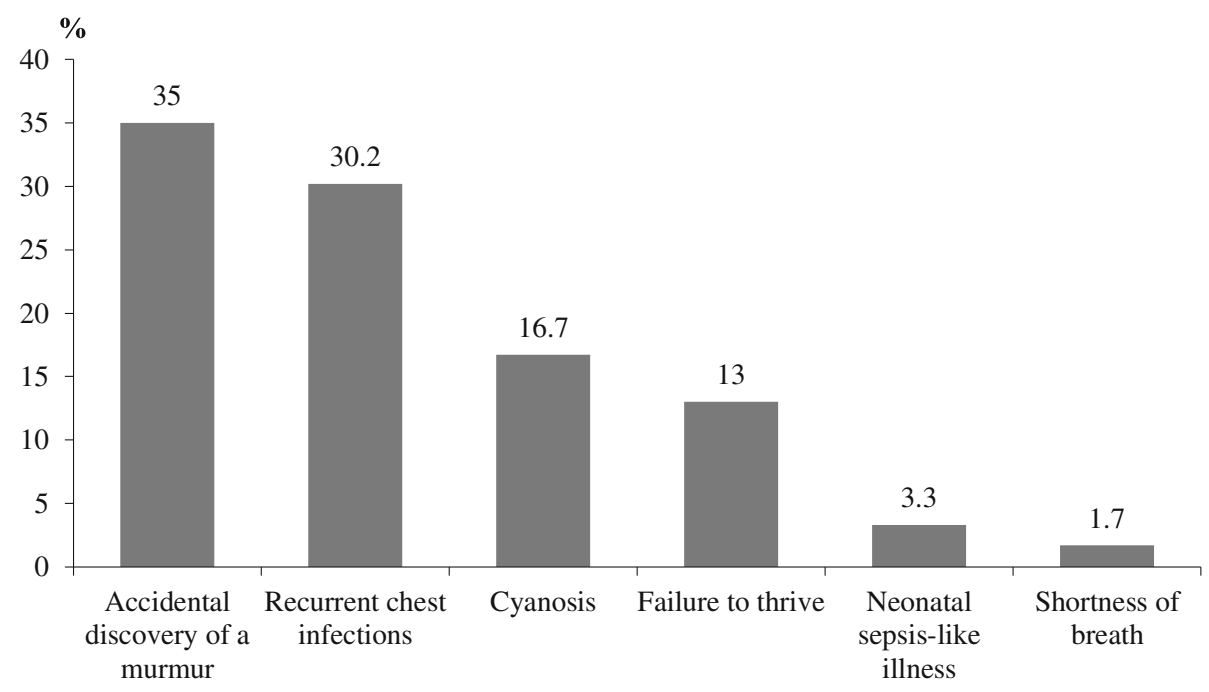

Fig. 1 Mode of presentation among studied population 
Table 2 Distribution of demographic data and risk factors

\begin{tabular}{|c|c|c|c|}
\hline \multicolumn{2}{|l|}{ Demographic/risk factor } & \multirow{2}{*}{$\begin{array}{l}\text { Number }(n=1005) \\
543\end{array}$} & \multirow{2}{*}{$\begin{array}{l}\text { Percentage (\%) } \\
54\end{array}$} \\
\hline Sex & Male & & \\
\hline & Female & 462 & 46 \\
\hline \multirow[t]{2}{*}{ Residency } & Urban & 790 & 78.6 \\
\hline & Rural & 215 & 21.4 \\
\hline \multirow[t]{3}{*}{ Maternal education } & Primary & 586 & 58.3 \\
\hline & Secondary & 150 & 14.9 \\
\hline & Illiterate & 269 & 26.8 \\
\hline \multirow[t]{3}{*}{ Maternal occupation } & Housewife & 922 & 91.7 \\
\hline & Manual worker & 72 & 7.2 \\
\hline & Desk job & 11 & 1.1 \\
\hline \multirow[t]{3}{*}{ Paternal occupation } & Farmer & 187 & 18.6 \\
\hline & Manual worker & 581 & 57.8 \\
\hline & Desk job & 237 & 23.6 \\
\hline \multirow[t]{2}{*}{ Parity } & Nulliparous & 339 & 33.7 \\
\hline & Multiparous & 666 & 66.3 \\
\hline \multirow[t]{4}{*}{ Maternal age at conception (years) } & $\leq 19$ & 427 & 42.5 \\
\hline & $20-29$ & 491 & 48.8 \\
\hline & $30-34$ & 28 & 2.8 \\
\hline & $>35$ & 59 & 5.9 \\
\hline Consanguinity & & 448 & 44.6 \\
\hline Prematurity & & 194 & 19.3 \\
\hline Assisted reproduction & & 118 & 11.7 \\
\hline Family history of CHD & & 93 & 9.2 \\
\hline Abortions & & 71 & 7.1 \\
\hline \multirow[t]{4}{*}{ Maternal medical illnesses } & Diabetes & 280 & 27.9 \\
\hline & Bronchial asthma & 146 & 14.5 \\
\hline & Hypertension & 74 & 7.4 \\
\hline & Epilepsy & 42 & 4.2 \\
\hline \multirow[t]{3}{*}{ Syndromes } & Down S & 105 & 10.4 \\
\hline & Disgorge S & 13 & 1.3 \\
\hline & Others & 50 & 5 \\
\hline \multirow[t]{3}{*}{ Extracardiac anomalies } & Inguinal hernia & 14 & 1.4 \\
\hline & Diaphragmatic hernia & 9 & 0.9 \\
\hline & Others & 13 & 1.3 \\
\hline
\end{tabular}

Data present in number and percentage

detected them in $3.5 \%$ and $21.8 \%$ respectively and detected $9 \%$ prevalence of $\mathrm{CHD}$ among first-degree relatives. Also, Nabulsi et al. [5] and AL-Ani [30] detected consanguinity rates of $34.7 \%$ and $77.9 \%$, respectively. The differences among various studies reflect the differences in the prevalence of consanguinity among different societies. Moreover, the high-risk factor in closely related parents indicates that consanguinity may act as a genetic predisposition that increases the susceptibility of developing $\mathrm{CHD}$, especially when there is exposure to an environmental risk factor. This highlights the need for public health education regarding the hazards of inbreeding.

In this study, one hundred and eighteen patients (11.7\% of our studied population) were the product of assisted reproduction. Children conceived via modern technologies are thought to be at a higher risk for developing birth defects, including CHD [31]. Koivurova et al. [32] detected a fourfold increase in the incidence of CHD among fetuses conceived via in vitro fertilization 
(IVF). Also, Tararbit et al. [33] found a $40 \%$ increase in the risk of CHD among those children.

Chromosomal anomalies account for $(8-10 \%)$ of syndromatic CHDs [34] with Down syndrome (DS) being the most common chromosomal anomaly seen among them [35]. In this study, syndromatic CHD was present in $16.7 \%$ of the studied population $(62.5 \%$ of them were DS). Fung et al. [29] detected genetic and syndromatic CHD in $9.5 \%$ of their studied population. There is geographic variability in the type of the dominant cardiac lesion seen in DS among different countries [36]. In this study, the atrioventricular septal defect was the commonest lesion seen among DS (40.3\%). This matches with Benhaourech et al. [37].

The pattern of maternal age as a hazardous factor for congenital defects differs among different countries which imply possible underlying genetic and environmental background rather than only the biological age [38]. Some studies suggested that the gynecological immaturity [39], lack of proper antenatal care, low socioeconomic class, poor diet, and other environmental nonbiological factors account for birth defects among young mothers [40]. Other studies had observed the prevalence of CHDs among older mothers [41, 42], whereas Best and Rankin [43] failed to find a strong evidence to support that advanced maternal age is a risk factor for CHD. Older maternal age has been linked to chromosomal-related congenital abnormalities while the risk of maternal age on the non-chromosomal abnormalities is considered negligible [38]. In this study, most of our patients $(91.3 \%)$ belonged to young mothers $(<29$ years old), only $5.9 \%$ belonged to mothers older than 35 years at conception, and only $16.7 \%$ were associated with syndromatic and chromosomal abnormalities.

Various studies had shown the effect of maternal diabetes as a risk factor for fetal cardiac malformations [44], as well as maternal hypertension, cigarette smoking, and other maternal chronic illnesses [22]. In this study, maternal diabetes, asthma, hypertension, and epilepsy were found in $27.9 \%, 14.5 \%, 7.4 \%$, and $4.2 \%$ of the studied population, respectively.

Though the exact etiological factors that link the association between increasing maternal parity and the risk of CHD is still unclear, theories include nutrient depletion especially folic acid [45], short inter-pregnancy periods [46], intrauterine exposure to teratogenic viruses (such as rubella) from children sharing the same home environment [47], biological changes in the intrauterine environment and psychological stress in pregnant mothers who are taking care of many children [48]. In this study, most of the patients (66.3\%) were born to multiparous mothers, while $33.7 \%$ were born to nulliparous mothers. This matches with the meta-analysis done by Yu et al. [49].
In this study, abortions occurred in $7.1 \%$ of the studied population. In contrast to $\mathrm{Li}$ et al. [50] who failed to find an association between bad obstetric history, recurrent abortions, and the risk of CHD, Abqari et al. [6] detected such an association. Also, Feng et al. [51] found that mothers will have a $24 \%$ higher risk of cardiac anomalies in their children if they experienced repeated abortions before. Etiological arguments include possible uterine factors that influence the implanted embryo [52] and associated chronic maternal illnesses [53]. In this study, we also detected prematurity in $19.3 \%$ of our studied patients. Tanner et al. [54] found that preterm infants are 2-times prone to CHD when compared to term infants; they detected prematurity in $16 \%$ of their CHD patients.

\section{Study limitations}

This work was not designed to study the risk factors as predictors for the occurrence of CHD; instead, it aimed at detecting the frequency of occurrence of those risk factors already documented in literature-among our studied population. Moreover, due to missing data in files, not all the known risk factors were studied, such as maternal body mass index, anemia, nutritional status, antenatal vitamin, and folic acid supplementation. Furthermore, the exact antenatal timing of exposure to teratogen was also missing. In addition, many patients had more than one underlying possible risk factor.

Multi-centric similar studies are needed to be done in different governorates, different geographical areas, Upper and Lower Egypt, rural and urban areas, though we still believe that this study can be considered as a nidus for such studies as it was done in a large University tertiary referral center that receives patients from different geographical areas in Cairo Governorate including those critical, severe, and complicated cases that are neither managed in the Ministry of Health hospitals nor in the private sector.

\section{Conclusions}

This study represents a descriptive epidemiological review of the pattern, clinical spectrum, age of presentation, sex distribution, and risk factor portfolio of $\mathrm{CHD}$ among the Egyptian ethnicity. Establishment of a national medical birth registry containing all information about all births in Egypt is needed for adequate surveillance and monitoring of perinatal health problems and congenital birth defects so that preventive measures can be early implemented through interdepartmental collaborations between different medical specialities including obstetricians, pediatricians, and geneticists. Proper and detailed data collection should be fulfilled in the medical records of every single patient. 


\section{Abbreviations}

ASD: Atrial septal defect; AVSD: Atrioventricular septal defect; CHD: Congenital heart disease; DS: Down syndrome; HLH: Hypoplastic left heart; PDA: Patent ductus arteriosus; PS: Pulmonary stenosis; TAPVR: Total anomalous pulmonary venous return; TGA: Transposition of great arteries; VSD: Ventricular septal defect

\section{Acknowledgements}

We thank the manager of the Children Hospital and the Head of Pediatric Cardiology Unit for their support.

\section{Authors' contributions}

Both authors conceived the idea and designed the study model. MM collected data from the files data, analyzed the data, and wrote the manuscript. YA revised the work. Both authors have read and approved the manuscript.

\section{Funding}

None.

\section{Availability of data and materials}

All data generated or analyzed during this study are included in this published article.

\section{Ethics approval and consent to participate}

This research protocol was approved by the Ethics committee of the Pediatric Department, Ain Shams University.

Committee Reference number: not available and not applicable as this was not a clinical trial (we did nothing to the patients for the sake of the study). This was a retrospective study, all data were recruited from the files. No sampling, experiments, or even clinical examination were done for the patients for the sake of this research work.

\section{Consent for publication}

Written informed consents were obtained from the participants' parents or their legal guardians in children who are under the age of 16 years.

\section{Competing interests}

None.

\section{Author details}

${ }^{1}$ Pediatric Department, Faculty of Medicine, Ain Shams University, Cairo, Egypt. ${ }^{2}$ Al-Salam International Hospital/Doctor Residency Building, P.O. Box 11023, Bneid Al Gar, Kuwait. ${ }^{3}$ Cardiology Department, Faculty of Medicine, Ain Shams University, Cairo, Egypt.

Received: 31 July 2020 Accepted: 12 January 2021

Published online: 29 January 2021

\section{References}

1. Bolisetty S, Daftary A, Ewald D et al (2004) Congenital heart defects in Central Australia. Med J Aust 180:614-617. https://doi.org/10.5694/j.13265377.2004.tb06122.x

2. Kapoor R, Gupta S (2008) Prevalence of congenital heart disease, Kanpur, India. Indian Pediatr 45:309-311

3. Otaigbe BE, Tabansi PN (2014) Congenital heart disease in the Niger Delta region of Nigeria: a four-year prospective echocardiographic analysis: cardiovascular topic. Cardiovasc J Afr 25:265-268. https://doi.org/10.5830/ CVJA-2014-055

4. Wren C, Richmond S, Donaldson L (1999) Presentation of congenital heart disease in infancy: implications for routine examination. Arch Dis Child Fetal Neonatal Ed 80:F49-F53. https://doi.org/10.1136/fn.80.1.F49

5. Nabulsi MM, Tamim H, Sabbagh M et al (2003) Parental consanguinity and congenital heart malformations in a developing country. Am J Med Genet 116A:342-347. https://doi.org/10.1002/ajmg.a.10020

6. Abqari S, Gupta A, Shahab T et al (2016) Profile and risk factors for congenital heart defects: a study in a tertiary care hospital. Ann Pediatr Cardiol 9:216. https://doi.org/10.4103/0974-2069.189119

7. Bassili A, Mokhtar SA, Dabous NI et al (2000) Risk factors for congenital heart diseases in Alexandria, Egypt. Eur J Epidemiol 16:805-814
8. Alabdulgader AA (2001) Congenital heart disease in 740 subjects: epidemiological aspects. Ann Trop Paediatr 21:111-118 https://doi.org/ 11471253

9. Johar D, Ahmed SM, El Hayek S et al (2019) Diabetes-induced proteome changes throughout development. Endocr Metab Immune Disord Drug Targets 19:732-743. https://doi.org/10.2174/1871530319666190305153810

10. Abushouk Al, El-Husseny MWA, Bahbah El et al (2017) Peroxisome proliferator-activated receptors as therapeutic targets for heart failure. Biomed Pharmacother 95:692-700. https://doi.org/10.1016/j.biopha.2017.08. 083

11. George IO, Frank-Briggs Al (2009) Pattern and clinical presentation of congenital heart diseases in Port-Harcourt. Niger J Med 18:211-214

12. Ainsworth SB, Wyllie JP, Wren C (1999) Prevalence and clinical significance of cardiac murmurs in neonates. Arch Dis Child - Fetal Neonatal Ed 80:F43F45. https://doi.org/10.1136/fn.80.1.F43

13. Bernstein D (2004) Congenital heart disease. In: Nelson Textbook of Pediatrics, 17th edn. Canada: Hardback; Elsevier Health Sciences

14. Subramanyan R, Joy J, Venugopalan P et al (2000) Incidence and spectrum of congenital heart disease in Oman. Ann Trop Paediatr 20:337-341. https://doi.org/10.1080/02724936.2000.11748155

15. Bassili A, Mokhtar SA, Dabous NI, Zaher SR, Mokhtar MMZA (2000) Congenital heart disease among school children in Alexandria, Egypt: an overview on prevalence and relative frequencies. J Trop Pediatr 46:357-362 https://doi.org/10.1093/tropej/46.6.357

16. Ibadin MO, Sadoh WE, Osarogiabon W (2005) Congenital heart diseases at the University of Benin Teaching Hospital.pdf. Niger J Paediatr 32:29-32

17. Ramachandra N, Smitha R, Karat S et al (2006) Prevalence of congenital heart diseases in Mysore. Indian J Hum Genet 12:11. https://doi.org/10.4103/ 0971-6866.25296

18. Sani MU, Mukhtar-Yola M, Karaye KM (2007) Spectrum of congenital heart disease in a tropical environment: an echocardiography study. J Natl Med Assoc 99:665-669 https://doi.org/17595936

19. Massin MM, Astadicko I, Dessy H (2008) Epidemiology of heart failure in a tertiary pediatric center. Clin Cardiol 31:388-391. https://doi.org/10.1002/clc. 20262

20. Sommers C, Nagel BHP, Neudorf U, Schmaltz AA (2005) Congestive heart failure in childhood. An epidemiologic study. Herz 30:652-662. https://doi. org/10.1007/s00059-005-2596-6

21. Botto LD, Lin AE, Riehle-Colarusso T et al (2007) Seeking causes: classifying and evaluating congenital heart defects in etiologic studies. Birth Defects Res A Clin Mol Teratol 79:714-727. https://doi.org/10.1002/bdra.20403

22. Liu S, Joseph KS, Lisonkova S et al (2013) Association between maternal chronic conditions and congenital heart defects. Circulation 128:583-589. https://doi.org/10.1161/CIRCULATIONAHA.112.001054

23. Chia S-E, Shi LM, Chan OY et al (2004) A population-based study on the association between parental occupations and some common birth defects in Singapore (1994-1998). J Occup Environ Med 46:916-923

24. Thulstrup AM, Bonde JP (2006) Maternal occupational exposure and risk of specific birth defects. Occup Med 56:532-543. https://doi.org/10.1093/ occmed/kql115

25. Mokhtar MM, Abdel-Fattah MM (2001) Consanguinity and advanced maternal age as risk factors for reproductive losses in Alexandria, Egypt. Eur J Epidemiol 17:559-565

26. Becker SM, Al Halees Z, Molina C, Paterson RM (2001) Consanguinity and congenital heart disease in Saudi Arabia. Am J Med Genet 99:8-13

27. Rittler M, Liascovich R, López-Camelo J, Castilla EE (2001) Parental consanguinity in specific types of congenital anomalies. Am J Med Genet 102:36-43

28. Haq FU, Jalil F, Hashmi S et al (2011) Risk factors predisposing to congenital heart defects. Ann Pediatr Cardiol 4:117. https://doi.org/10.4103/0974-2069. 84641

29. Fung A, Manlhiot C, Naik S et al (2013) Impact of prenatal risk factors on congenital heart disease in the current era. J Am Heart Assoc 2. https://doi.org/10.1161/JAHA.113.000064

30. Al-Ani ZR (2010) Association of consanguinity with congenital heart diseases in a teaching hospital in Western Iraq. Saudi Med J 31:1021-1027

31. Sutcliffe AG, Ludwig M (2007) Outcome of assisted reproduction. Lancet 370:351-359. https://doi.org/10.1016/S0140-6736(07)60456-5

32. Koivurova S (2002) Neonatal outcome and congenital malformations in children born after in-vitro fertilization. Hum Reprod 17:1391-1398. https://doi.org/10.1093/humrep/17.5.1391 
33. Tararbit K, Houyel L, Bonnet D et al (2011) Risk of congenital heart defects associated with assisted reproductive technologies: a population-based evaluation. Eur Heart J 32:500-508. https://doi.org/10. 1093/eurheartj/ehq440

34. Roos-Hesselink JW, Kerstjens-Frederikse WS, Meijboom FJ, Pieper PG (2005) Inheritance of congenital heart disease. Neth Heart J 13:88-91

35. Bull MJ (2011) Health supervision for children with Down syndrome. Pediatrics 128:393-406. https://doi.org/10.1542/peds.2011-1605

36. Narayanan DL, Yesodharan D, Kappanayil M et al (2014) Cardiac spectrum, cytogenetic analysis and thyroid profile of 418 children with Down syndrome from South India: a cross-sectional study. Indian J Pediatr 81:547551. https://doi.org/10.1007/s12098-013-1088-6

37. Benhaourech S, Drighil A, El Hammiri A (2016) Congenital heart disease and Down syndrome: various aspects of a confirmed association. Cardiovasc J Afr 27:287-290. https://doi.org/10.5830/CVJA-2016-019

38. Loane M, Dolk H, Morris J (2009) Maternal age-specific risk of nonchromosomal anomalies. BJOG 116:1111-1119. https://doi.org/10.1111/j. 1471-0528.2009.02227.x

39. Raatikainen K, Heiskanen N, Verkasalo PK, Heinonen S (2006) Good outcome of teenage pregnancies in high-quality maternity care. Eur J Public Health 16:157-161. https://doi.org/10.1093/eurpub/cki158

40. Wahn EH, Nissen E (2008) Sociodemographic background, lifestyle and psychosocial conditions of Swedish teenage mothers and their perception of health and social support during pregnancy and childbirth. Scand J Public Health 36:415-423. https://doi.org/10.1177/1403494807085315

41. Reefhuis J, Honein MA (2004) Maternal age and non-chromosomal birth defects, Atlanta--1968-2000: teenager or thirty-something, who is at risk? Birth Defects Res A Clin Mol Teratol 70:572-579. https://doi.org/10.1002/ bdra.20065

42. Miller A, Riehle-Colarusso T, Siffel $\mathrm{C}$ et al (2011) Maternal age and prevalence of isolated congenital heart defects in an urban area of the United States. Am J Med Genet A 155A:2137-2145. https://doi.org/10.1002/ ajmg.a.34130

43. Best KE, Rankin J (2016) Is advanced maternal age a risk factor for congenital heart disease? Birth Defects Res A Clin Mol Teratol 106:461-467. https://doi.org/10.1002/bdra.23507

44. Nielsen GL, Norgard B, Puho E et al (2005) Risk of specific congenital abnormalities in offspring of women with diabetes. Diabet Med 22:693-696. https://doi.org/10.1111/j.1464-5491.2005.01477.x

45. Hernández-Díaz S, Werler MM, Walker AM, Mitchell AA (2000) Folic acid antagonists during pregnancy and the risk of birth defects. N Engl J Med 343:1608-1614. https://doi.org/10.1056/NEJM200011303432204

46. Grisaru-Granovsky S, Gordon E-S, Haklai Z et al (2009) Effect of interpregnancy interval on adverse perinatal outcomes--a national study. Contraception 80:512-518. https://doi.org/10.1016/j.contraception.2009.06. 006

47. Stuckey D (1956) Congenital heart defects following maternal rubella during pregnancy. Heart 18:519-522. https://doi.org/10.1136/hrt.18.4.519

48. Zhu JL, Olsen J, Sørensen HT et al (2013) Prenatal maternal bereavement and congenital heart defects in offspring: a registry-based study. Pediatrics 131:e1225-e1230. https://doi.org/10.1542/peds.2012-3024

49. Feng Y, Yu D, Chen T et al (2014) Maternal parity and the risk of congenital heart defects in offspring: a dose-response meta-analysis of epidemiological observational studies. PLoS One 9:e108944. https://doi.org/10.1371/journal. pone.0108944

50. Li N-N, Chen X-L, Liu Z et al (2015) Maternal abortion history and the risk of congenital heart defects. A case-control study. J Reprod Med 60:236-242 https://doi.org/26126309

51. Feng $Y$, Wang S, Zhao L et al (2015) Maternal reproductive history and the risk of congenital heart defects in offspring: a systematic review and metaanalysis. Pediatr Cardiol 36:253-263. https://doi.org/10.1007/s00246-0141079-z

52. Rushton DI (1978) Simplified classification of spontaneous abortions. J Med Genet 15:1-9. https://doi.org/10.1136/jmg.15.1.1

53. Petrescu A, Berdan G, Hulea I et al (2007) Small cell carcinoma of the urinary bladder--a new case report. Rom J Morphol Embryol 48:309-314 https://doi. org/17914502

54. Tanner K, Sabrine N, Wren C (2005) Cardiovascular malformations among preterm infants. Pediatrics 116:e833-e838. https://doi.org/10.1542/peds. 2005-0397

\section{Publisher's Note}

Springer Nature remains neutral with regard to jurisdictional claims in published maps and institutional affiliations.

\section{Submit your manuscript to a SpringerOpen ${ }^{\circ}$ journal and benefit from:}

- Convenient online submission

- Rigorous peer review

- Open access: articles freely available online

- High visibility within the field

- Retaining the copyright to your article

Submit your next manuscript at $\boldsymbol{\nabla}$ springeropen.com 